\title{
Importance of the control group in scientific research
}

Matheus Melo Pithon*

Fundamentally, scientific research aims at contributing to the development of human knowledge in all areas, being systematically planned and executed according to rigorous criteria of information processing. ${ }^{1}$ It consists of investigations, observations and experiments, and tries to use these tools to explain the causes of many phenomena.

When reading scientific articles of which purpose is to experiment, we find the so-called control group. What would that be? What is the importance and need of a control group in a scientific study? The objective of the present article is to present, in a clear and objective manner, the importance of including a control group in scientific research.

The control group consists of elements that present exactly the same characteristics of the experimental group, except for the variable applied to the latter. ${ }^{2}$ This group of scientific control enables the experimental study of one variable at a time, and it is an essential part of the scientific method. In a controlled experiment, two identical experiments are carried out: in one of them, the treatment or tested factor (experimental group) is applied; whereas in the other group (control), the tested factor is not applied. ${ }^{2}$

How to cite this article: Pithon MM. Importance of the control group in scientific research. Dental Press J Orthod. 2013 Nov-Dec;18(6):13-4.

Submitted: October 09, 2013 - Revised and accepted: October 23, 2013

*Professor of Orthodontics, State University of Southwest Bahia (UESB).
A good example for us, orthodontists, is the assessment of the influence of medicine over orthodontic tooth movement. In these cases, it is important to examine if the supposed effects of the applied drug are produced only by the drug. In this situation, identical groups of patients or animals are compared, one of them receives the drug and the other receives a placebo or, in many cases, does not receive any drug (control group). In order to avoid bias, it is always important to prevent not only the researchers, but also the individuals who will receive the medicine from knowing which group receives the real drug.

In Orthodontics, as in any specialty in the Health field, it is difficult to establish a control group for clinical studies, given that many ethical implications are involved. A good example to demonstrate this situation is the proposal of a study focused on the assessment of a new method for skeletal Class II malocclusion treatment of patients in craniofacial growth. The ideal control group, in this case, would comprise patients with the same characteristics of those in the experimental group, including age, race, maturation stage, same tendency for craniofacial growth. However, to be in the control group,

Contact address: Matheus Melo Pithon Av. Otávio Santos, 395, sala 705 - Centro Odontomédico Dr. Altamirando da Costa Lima - Recreio, Vitória da Conquista/BA - Brazil. CEP 45.020-750

E-mail: matheuspithon@gmail.com 
patients should not be orthopedically treated, precisely in the ideal phase for treatment. In these situations, an ethical issue arises: How can we carry out an experiment without causing any damage to patients? In situations like these, it is acceptable that the patients in the control group be subjected to procedures already established in literature ${ }^{3}-$ which, in this particular case, would consist of treatment performed with extraoral appliances (considered as gold standard in the treatment of malocclusion).

Although not ideal, given that we would not have a control group without any involved factor, this approach meets the ethical requirements that currently surround us.
A more delicate situation involves studies that use computed tomography as a method of diagnosis. We are currently experiencing an avalanche of scientific researches using this new technology. Its use has facilitated diagnosis and orthodontic planning, however, when we think about scientific research - and, more precisely, about control groups - , the following question arises: Would we be exposing our patients to unnecessary risks? Considering that by using this tool in a study that contains a control group we would be exposing the patient to two situations: the absence of treatment and the unnecessary exposure to ionizing radiation, we should think about it. Food for thought.
REFERENCES

1. Gu J, Li XB, Tian LH. [Scientific research accomplishment of medical staff]. Zhonghua Yi Xue Za Zhi. 2013 Mar 12;93(10):735-7.

2. Kinser PA, Robins JL. Control group design: enhancing rigor in research of mind-body therapies for depression. Evid-Based Complement Alternat Med. 2013;2013:140467.

3. Bertone J. Ethical, scientific and practical standards in clinical practice research. Equine Vet J. 2013 Jul:45(4):391-3. 